\title{
A NOVEL GLYCOPROTEIN OF FELINE INFECTIOUS PERITONITIS CORONAVIRUS CONTAINS A KDEL-LIKE ENDOPLASMIC RETICULUM RETENTION SIGNAL
}

\author{
H. Vennema ${ }^{1}$, L. Heijnen ${ }^{2}$, P.J.M. Rottier ${ }^{1}$, M.C. Horzinek ${ }^{1}$ and \\ W.J.M. Spaan ${ }^{2}$ \\ ${ }^{1}$ Department of Virology, Faculty of Veterinary Medicine, University \\ of Utrecht, Yalelaan 1, P.O. Box 80.165, 3508 TD Utrecht, The \\ Netherlands. \\ ${ }^{2}$ Department of Virology, Faculty of Medicine, University of Leiden, \\ The Netherlands
}

\begin{abstract}
A new protein of the feline infectious peritonitis virus (FIPV) was discovered in lysates of infected cells. Expression of the gene encoding open reading frame (ORF) $6 \mathrm{~b}$ of FIPV in recombinant vaccinia virus infected cells was used to identify it as the $6 \mathrm{~b}$ protein. It is a novel type of viral glycoprotein whose function is not clear. It is a soluble protein contained in microsomes; its slow export from the cell is caused by the presence of an ER-retention signal at the C-terminus. This amino acid sequence, KTEL, closely resembles the consensus KDEL-signal of soluble resident ER proteins. A mutant $6 \mathrm{~b}$ protein with the $\mathrm{C}$-terminal sequence $\mathrm{KTEV}$ became resistant to digestion by endo- $\beta-N$-acetylglucosaminidase $\mathrm{H}$ with a half-time that was reduced threefold. In contrast, a mutant with the sequence KDEL was completely retained in the ER. The FIPV $6 \mathrm{~b}$ protein is the first example of a viral protein with a functional KDEL-like ER-retention signal.
\end{abstract}

\section{INTRODUCTION}

The feline infectious peritonitis virus (FIPV) and transmissible gastroenteritis virus (TGEV) of swine are genetically closely related. However, FIPV contains a complete open reading frame (ORF-2) in the 3' region of the genome, which is lacking in TGEV (1). ORF-2 is located 3' from ORF-1 of mRNA 6 and we suggested that it is produced from a bicistronic mRNA. According to the recently proposed nomenclature (2) the first and second ORF of mRNA 6 are now called ORF $6 \mathrm{a}$ and ORF $6 \mathrm{~b}$, respectively. The FIPV ORF $6 \mathrm{~b}$ potentially encodes a polypeptide of 24 -kilodalton $(\mathrm{kDa})$, it contains 
a short $\mathrm{N}$-terminal hydrophobic region (1), which may function as a signal sequence, and one consensus $\mathrm{N}$-glycosylation site. In this report we show that the protein encoded by ORF $6 \mathrm{~b}$ is produced in FIPV-infected cells and that it is a novel type of viral glycoprotein.

\section{MATERIALS AND METHODS}

\section{Cells and viruses}

FIPV strain 79-1146 (3) was grown in Crandell feline kidney (CrFK) cells. For vaccinia virus infections, HeLa cells were used. Cells were maintained in Dulbecco modified Eagle medium (GIBCO Laboratories) containing 5\% fetal bovine serum.

\section{Radio immunoprecipitation assays (RIPA)}

FIPV or vaccinia virus infected cells were labeled with $\mathrm{L}-\left[{ }^{35} \mathrm{~S}\right]$ methionine or L$\left.{ }^{35} \mathrm{~S}\right]$ cysteine $(>1,000 \mathrm{Ci} / \mathrm{mmol}$, Amersham Corp.). Lysis, radio immunoprecipitation assay (RIPA) and endo- $\beta$ - $N$-acetylglucosaminidase $\mathrm{H}$ (endo H, Boehringer Mannheim Biochemicals) treatment were carried out as described (4). Analysis by sodium dodecyl sulphate polyacrylamide gel electrophoresis (SDS-PAGE) was as described (5).

\section{Cloning and expression of ORF $6 \mathrm{~b}$}

A cDNA fragment extending from a SpeI-site, located 84 base pairs upstream of the initiation codon of ORF $6 \mathrm{~b}$ to a Sall-site in the polylinker of cDNA clone E7 (1) was recloned in a bacteriophage $\mathrm{T} 7$ expression vector. The resulting construct, was designated pTF6b.

\section{RESULTS}

\section{Identification of the FIPV $6 \mathrm{~b}$ protein}

ORF $6 \mathrm{~b}$ of FIPV contains one methionine codon and seven cysteine codons. The electrophoretic patterns of immunoprecipitated lysates from $\left[{ }^{35}\right.$ S]methionine and $\left[{ }^{35}\right.$ S $]$ cysteine labeled FIPV-infected cells were compared to identify ORF $6 \mathrm{~b}$ derived polypeptides. After $\left[{ }^{35} \mathrm{~S}\right]$ methionine labeling the FIPV membrane protein (M) appeared as a strong band of $29 \mathrm{kDa}$ and a minor band of $26 \mathrm{kDa}$ (Fig. 1), corresponding to the glycosylated and the unglycosylated forms of the $M$ protein, respectively (4). In $\left.{ }^{35} \mathrm{~S}\right]$ cysteine labeled immunoprecipitates a double band was observed of 26 to 26.5 $\mathrm{kDa}$, at the position of the unglycosylated $\mathrm{M}$ protein band. When the samples were digested with endo $\mathrm{H}$, which cleaves asparagine-linked high mannose oligosaccharide side chains, a $24 \mathrm{kDa}$ protein was detected exclusively after $\left[{ }^{35} \mathrm{~S}\right]$ cysteine labeling (Fig. 1). To test the hypothesis that ORF $6 \mathrm{~b}$ encodes this glycoprotein, the $6 \mathrm{~b}$ gene was recloned into a bacteriophage T7 expression vector. The resulting construct, designated pTF6b, was used in the transient T7 expression system with recombinant vaccinia virus vTF7-3 producing the T7 RNA polymerase (6). The protein detected after immunoprecipitation comigrated with the $26.5 \mathrm{kDa}$ protein from FIPV-infected cells (Fig. 1). Digestion with endo $\mathrm{H}$ yielded a protein which comigrated with the $24 \mathrm{kDa}$ protein mentioned above. 


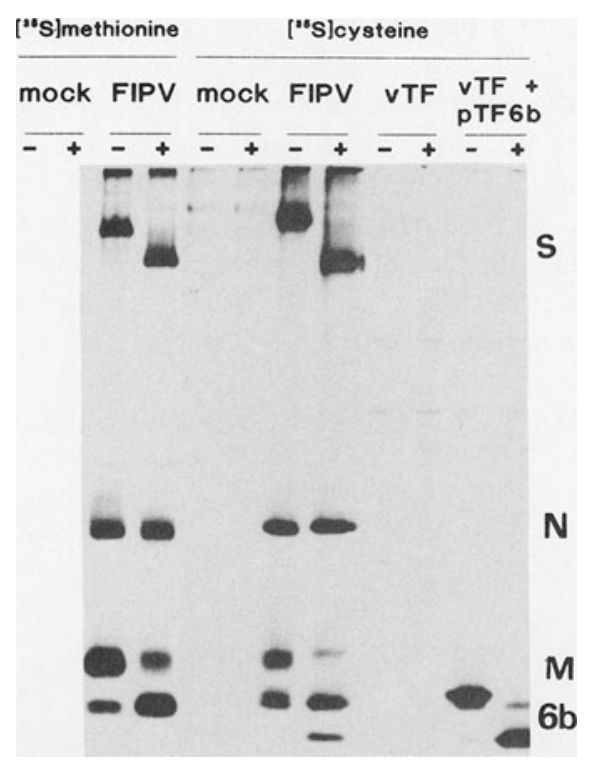

Figure 1. Identification of the $6 \mathrm{~b}$ protein. RIPA and SDS-PAGE analysis of lysates from infected cells. Immunoprecipitates were split and one half was treated with endo $\mathrm{H}$, the other serving as a control (indicated by + and -, respectively). FIPV- and mock-infected cells were labeled at $5 \mathrm{~h}$ p.i. with $\left[{ }^{35} \mathrm{~S}\right]$ methionine or $\left.{ }^{35} \mathrm{~S}\right]$ cysteine. Recombinant vaccinia virus vTF7-3-infected and transfected cells (lanes marked VTF and vTF + pTF6b, respectively) were labeled with $\left[{ }^{35} \mathrm{~S}\right]$ cysteine.

To prove that the recombinant $6 \mathrm{~b}$ protein and the 26 to $26.5 \mathrm{kDa}$ protein in FIPVinfected cells are the same, we set up a competition RIPA. Unlabeled recombinant $6 \mathrm{~b}$ protein producing cells was added to lysate from $\left[{ }^{35} \mathrm{~S}\right]$ cysteine labeled FIPV-infected cells. The samples were then immunoprecipitated. This resulted in a decreased intensity of the 26 to $26.5 \mathrm{kDa}$ doublet, but not of the FIPV M protein band (Fig. 2A). The same was done with recombinant $\mathrm{M}$ protein. This resulted in a decrease of $\mathrm{M}$ protein band intensity (Fig. 2B).

A rec. $6 b$ protein

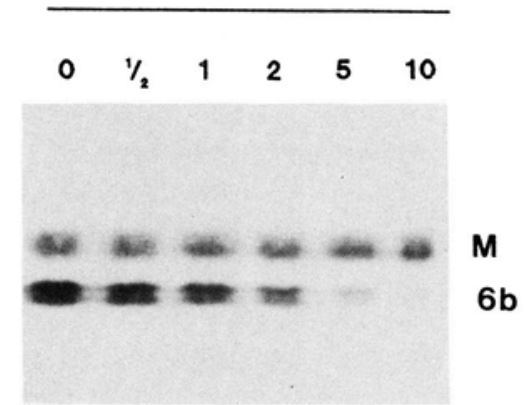

B rec. $M$ protein

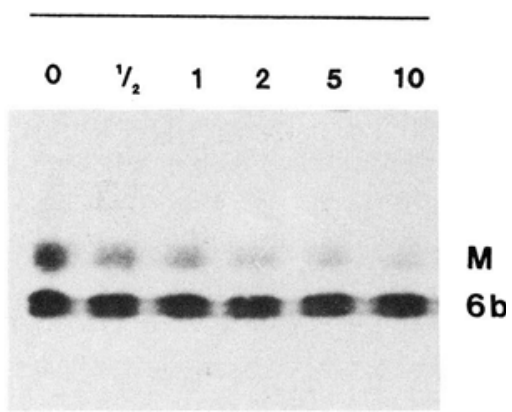

Figure 2. Competition of immunoprecipitation with recombinant $6 \mathrm{~b}$ and $\mathrm{M}$ proteins. Lysate from recombinant $6 \mathrm{~b}$ (panel $\mathrm{A}$ ) or $\mathrm{M}$ (panel B) protein producing cells were added to samples of $\left[{ }^{35} \mathrm{~S}\right]$ cysteine labeled lysate of FIPV-infected cells and processed for RIPA. The relative amount of unlabeled cell lysate is indicated above each lane. 
Isolation of closed and opened microsomal membranes showed that the $6 \mathrm{~b}$ protein is a membrane protein but not an integral membrane protein (7). Preliminary observations indicated that the $6 \mathrm{~b}$ protein is released into the medium of FIPV-infected cells. It remained to be determined whether the $6 \mathrm{~b}$ protein is a structural protein. Therefore, $\left.{ }^{35} S\right]$ cysteine labeled virus was pelleted from the medium of infected cells by centrifugation; pellet and supernatant fraction were processed for RIPA. The $6 \mathrm{~b}$ protein was found in the supernatant fraction but not in the pellet fraction where the structural proteins accumulated (Fig. 3). Consequently, the $6 \mathrm{~b}$ protein is not stably associated with extracellular virus particles produced in tissue culture.

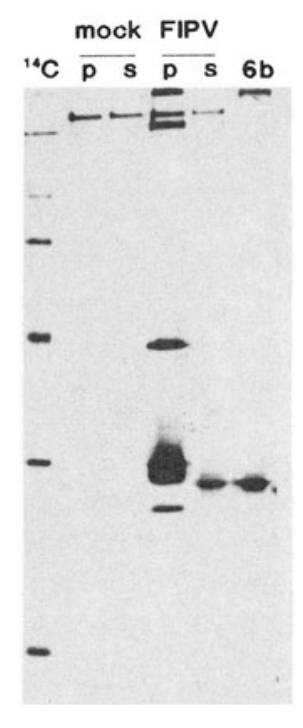

Figure 3. Virus purification. Radioactively labeled virus was purified by centrifugation. Pellet and supernatant (marked p and s, respectively) of mock- and FIPV-infected cells were processed for RIPA. Secreted recombinant $6 \mathrm{~b}$ protein and ${ }^{14} \mathrm{C}$-labeled marker proteins were run in parallel for comparison (lanes marked $6 \mathrm{~b}$ and ${ }^{14} \mathrm{C}$, respectively).

\section{Expression of C-terminally mutated $6 \mathrm{~b}$ protein genes}

Analysis of the intracellular transport of the $6 \mathrm{~b}$ protein showed that it is transported very slowly, in particular when using the recombinant vaccinia virus expression system (7). The $6 \mathrm{~b}$ protein C-terminal sequence, KTEL, is very similar to the KDEL-signal of cellular resident ER proteins (8). We hypothesized that the KDEL-like sequence of the $6 \mathrm{~b}$ protein caused its slow export from the ER. Therefore, we constructed a mutated version of the $6 \mathrm{~b}$ protein gene encoding the C-terminal sequence KTEV. This change has been demonstrated to abolish ER-retention $(9,10)$. The mutant construct, designated pTF6bV, was compared to the original construct in a pulse-chase experiment (Fig. 4). The $6 \mathrm{bV}$ protein was secreted into the medium faster than the wild-type expression product. It became endo $\mathrm{H}$ resistant with a half-time that was reduced threefold. Next, we changed the C-terminal sequence to $\mathrm{KDEL}$, to see if this would confer complete ER retention. The $6 \mathrm{bD}$ protein was analyzed in a pulse-chase experiment (Fig $4 \mathrm{C}$ ). It was completely retained in the ER during a $3 \mathrm{~h}$ chase period; it could not be detected in the medium and remained entirely endo $\mathrm{H}$ sensitive. These 

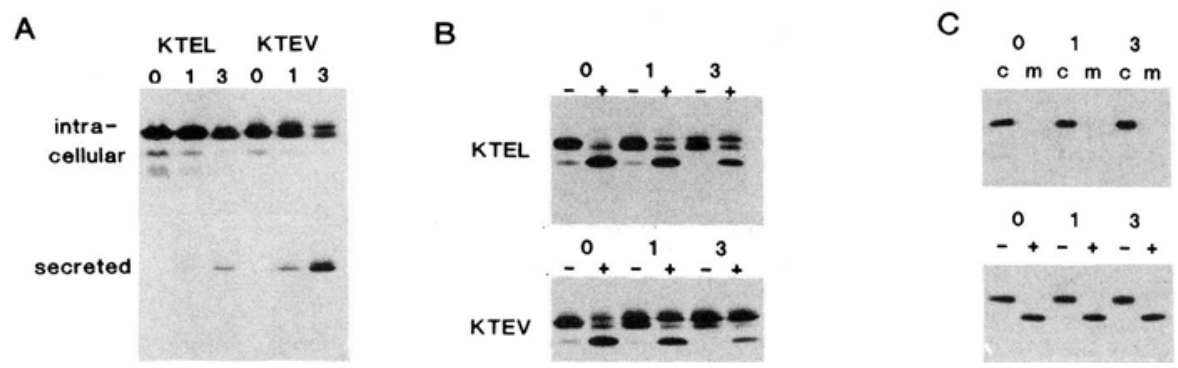

Figure 4. Pulse-chase analysis of wild-type and mutated $6 \mathrm{~b}$ proteins. Cells infected with vTF7-3 were transfected with pTF6b or pTF6bV (indicated by KTEL and KTEV, respectively), pulse-labeled for 1 $\mathrm{h}$ and analyzed immediately or after chase times of 1 and $3 \mathrm{~h}$, as indicated. Analysis was performed as described in the legends to Fig. 1. (A.) Intracellular and secreted polypeptides were analyzed separately. (B.) Lysates including the culture media were analyzed by endo $\mathrm{H}$ digestion. (C.) Similar experiments were performed with pTF6bD. Cells and medium were processed separately (indicated by $\mathrm{c}$ and $\mathrm{m}$, respectively). Intracellular material was subsequently analyzed after treatment with endo $\mathrm{H}$ or mock treatment (indicated by + and -, respectively).

experiments demonstrate that the original $\mathrm{C}$-terminal sequence of the FIPV $6 \mathrm{~b}$ protein confers partial ER-retention by the same mechanism as used for cellular resident ER proteins.

\section{DISCUSSION}

In this paper we report the identification and characterization of a new virus specific protein in FIPV-infected cells. A glycoprotein of $26.5 \mathrm{kDa}$ was detected in ${ }^{35}$ S $]$ cysteine but not in ${ }^{35}$ S $]$ methionine labeled cell lysates, which explains why it had not been observed before $(4,11)$. The protein was identified by recombinant gene expression of the second ORF of mRNA 6 (7), currently designated ORF 6b. Further studies showed that the $6 \mathrm{~b}$ protein is a soluble protein contained in microsomes, that it is secreted from infected cells, and that it is not stably associated with virus particles in tissue culture medium.

Detailed analysis of its intracellular transport showed that the $6 \mathrm{~b}$ protein was released slowly from the ER, particularly in recombinant vaccinia virus infected cells. The $6 \mathrm{~b}$ protein C-terminal sequence, KTEL, is almost identical to the KDEL-signal of resident ER proteins. This signal or a closely related sequence at the $\mathrm{C}$-terminus of a protein with an $\mathrm{N}$-terminal signal sequence are strong indications that it is a resident lumenal ER-protein (8). Proteins with a KDEL-signal are recognized by a receptor located in a compartment between the ER and the Golgi apparatus and recycled back to the ER. Site-directed mutagenesis of the signal to KTEV abolished retention. The wild-type $6 \mathrm{~b}$ protein was not completely retained in the ER, while mutagenesis of its C-terminus to KDEL resulted in complete ER retention.

The FIPV $6 \mathrm{~b}$ protein is the first example of a viral protein with a functional KDEL-like ER-retention signal.

\section{REFERENCES}

1. Groot, R.J. de, A.C. Andeweg, M.C. Horzinek, and W.J.M. Spaan. (1988) Virology 167:370-376.

2. Cavanagh, D., D.A. Brian, L. Enjuanes, K.V. Holmes, M.M.C. Lai, H. Laude, S.G. Siddell, W. Spaan, Taguchi, and P.J. Talbot. (1990) Virology 176:306-307.

3. McKeirnan, A.J., J.F. Evermann, A. Hargis, L.M. Miller, and R.L. Ott. (1981) Feline Pract. 11:16-20. 
4. Vennema, H., L. Heijnen, A. Zijderveld, M.C. Horzinek, and W.J.M. Spaan. (1990) J. Virol. 64:339-346.

5. Laemmli, U.K. (1970) Nature 227:680-685.

6. Fuerst, T.R., E.G. Niles, F.W. Studier, and B. Moss. (1986) Proc. Natl. Acad. Sci. USA 83:8122-8126.

7. Vennema, H., L. Heijnen, P.J.M. Rottier, M.C. Horzinek, and W.J.M. Spaan. (1992) J. Virol. 66:4951-4956.

8. Pelham, H.R.B. (1990) Trends in Biol. Sci. 15:483-486.

9. Andres, D.A., J.D. Rhodes, R.L. Meisel, and J.E. Dixon. (1991) J. Biol. Chem. 266: 14277-14282.

10. Zagouras, P., and J.K. Rose. (1989) J. Cell Biol. 109:2633-2640.

11. Groot, R.J. de, R.J. ter Haar, M.C. Horzinek, and B.A.M. van der Zeijst. (1987) J. Gen. Virol. 68:995-1002. 